\title{
Ultrasonic removal of pyridine from wastewater: optimization of the operating conditions
}

\author{
M. A. Elsayed
}

Received: 14 July 2013/Accepted: 24 March 2014/Published online: 5 April 2014

(C) The Author(s) 2014. This article is published with open access at Springerlink.com

\begin{abstract}
In this study, a fundamental research had been carried out to explore the removal of pyridine in wastewater by ultrasound radiation. The effects of initial pyridine concentration, radiation time, $\mathrm{pH}$, aeration, and the reaction temperature on the pyridine removal efficiency were investigated. The removal rates of pyridine at 180 min sonication time were found to decrease from 53 to $15 \%$ with increasing the initial concentration from 10 to $100 \mathrm{mg} / \mathrm{L}$. However, the total amount of pyridine degraded after $60 \mathrm{~min}$ at $100 \mathrm{mg} / \mathrm{L}$ was as much as three times larger than that degraded at $10 \mathrm{mg} / \mathrm{L}$. The optimal $\mathrm{pH}$ was found to be 9 which resulted in $25 \%$ pyridine removal after 180 min ultrasound radiation. By observing the change of $\mathrm{pH}$ value with the sonication time up to $60 \mathrm{~min}$, it was observed that, $\mathrm{pH}$ of the sonicated pyridine aqueous mixture has decreased from 9.2 to 6.2 during the irradiation. The decrease in the $\mathrm{pH}$ may be attributed due to the formation of peroxy radicals in the solution and subsequently formation of oxygen free radicals. The simultaneous aeration could improve pyridine removal efficiency of ultrasound irradiation by $24 \%$. With increasing media temperatures, the removal efficiencies of pyridine increased in the temperature range in this study. In the end, it could be proposed that ultrasound radiation was an effective method for the removal of pyridine from wastewater.
\end{abstract}

Keywords Pyridine - Ultrasound radiation - Wastewater treatment $\cdot \mathrm{pH} \cdot$ Degradation

M. A. Elsayed ( $\square)$

Egyptian Armed Forces, Cairo, Egypt

e-mail: aboelfotoh@gmail.com

\section{Introduction}

The increasingly acceptable use of chemicals in industries and households has resulted in the increasing generation of organic pollutants in effluents. These pollutants are potential health hazards. Enormous quantities of aromatic compounds as pollutants are being released into the environment by various industries (Jain et al. 2004), because of the broad range of applications of aromatic compounds among the top chemicals used in many industries (Gogate and Pandit 2004). Out of this aromatic heterocyclic compounds such as pyridine and its derivatives are of major concern as environmental pollutants due to their recalcitrant, toxic and teratogenic nature (Stapleton et al. 2006; Karthikeyan et al. 2012).

Pyridine was produced from coal tar and as a by-product of the coal gasification. However, increased demand for pyridine resulted in the development of more economical methods of synthesis from acetaldehyde and ammonia, and more than 20,000 tons per year are manufactured worldwide. Thus, researchers have long sought to develop effective, economically feasible techniques for cleaning the atmosphere of waste such as pyridine (Gupta et al. 2007a, b; Mittal et al. 2008; Saleh and Gupta 2012).

Various physicochemical methods for the wastewater treatment have been investigated (Goel et al. 2004; Mittal et al. 2010; Gupta et al. 2012). These include adsorption (Gupta et al. 2006, 2009, 2011), electrochemical (Gupta et al. 2007c), sorption using waste material (Gupta and Sharma 2003; Gupta et al. 2006, 2010; Mittal et al. 2010), biodegradation (Padoley et al. 2006; Mathur et al. 2008), and ozonation with biodegradation (Ince and Tezcanlí 2001; Agustina et al. 2005). After extensive search, a lack in literature reports on the removal of pyridine from wastewater by ultrasound radiation has been determined. 
Nowadays, ultrasonic irradiation has received considerable interest as an advanced oxidation process because it leads to rapid degradation of chemical contaminants in water (Abbasi and Asl 2008; Yang et al. 2009). Ultrasound can enhance or promote chemical reactions and mass transfer and offer the potential for shorter reaction cycles, cheaper reagents, and less extreme physical conditions (Gong and Hart 1998; Goel et al. 2004). So far, ultrasound has been applied in studies of cleaning, organic synthesis, catalysis, extraction, emulsification, material processing, food processing, and wastewater treatment (Vinodgopal et al. 1998; Naffrechoux et al. 2000; Saleh and Gupta 2012).

In this study, an investigation was focused on the ultrasonic degradation of pyridine in aqueous media. A variety of different operating conditions were examined. The effects of different initial concentration, $\mathrm{pH}$, aeration, and reaction temperatures on the degradation efficiency were investigated.

\section{Materials and methods}

\section{Materials}

Pyridine standard solution was supplied by Fluka with purity better than $98.0 \%$. It was used to prepare a synthetic wastewater. Aqueous solutions were made using deionized water, which was prepared by an Elga B114 Deionizer using $\mathrm{C} 114$ cartridges, (EC $5 \mu \mathrm{S} \mathrm{cm} 5{ }^{\circ} \mathrm{C}$ and TDS $3.5 \mathrm{ppm}$ ). All other reagents were reagent grad obtained from Fluka and used as received.

\section{Ultrasonic setup reactor}

The degradation experiments were carried out in ultrasonic cleaner bath (Honda electronics PS-60, Capacity $15 \mathrm{~L}$ ). The bath operates at $360 \mathrm{~W}$ and $40 \mathrm{kHz}$. Erlenmeyer flask was used as reaction vessel. The volume of the solution was $100 \mathrm{~mL}$. The bath temperatures were maintained by proper recirculation of water. Solution temperature was also monitored regularly. The efficiency of a reaction vessel placed in an ultrasonic bath depends strongly on the distance of the bottom of the reaction vessel to the bottom of water bath. The distance was carefully measured through preliminary experiments, so that ultrasonic intensity reached maximum at the bottom of the flask. For ultrasonic frequency $40 \mathrm{kHz}$ this distance value was $1 \mathrm{~cm}$. The reactor was sealed with silicone stopper wrapped with an aluminium foil to ensure the minimum loss due to evaporation of the volatile compounds. The syringe needle was pierced through the septum of the stopper for sampling. In the present study, ultrasonic device provides indirect sonication, which will inevitably cause energy loss. A limited quantity of energy is transmitted into the reaction vessel. So, it should be kept in mind that the power used is not the real power of ultrasonic energy transmitting into the reaction mixture. All sonochemical experiments were conducted twice in parallel. The averages of the parallel experimental data were calculated and taken into account in analyses of sonochemical kinetics. The error of all parallel experiments was under $5 \%$.

Quantitative analysis experiments

Quantitative analysis of Pyridine concentration was determined by measuring its absorbance using Shimadzu UVVisible spectrophotometer. Initially, tests were carried out by UV scans from a wavelength of 200-500 $\mathrm{nm}$ to determine the absorption maxima of the pyridine molecule.

\section{Results and discussion}

Study and optimization of the operating conditions

\section{Effect of initial pyridine concentration}

The effect of solute concentration on the degradation of pyridine was investigated at $\mathrm{pH} 6.7,40 \mathrm{kHz}, 20 \pm 1{ }^{\circ} \mathrm{C}$, $360 \mathrm{~W}$ and initial concentration 10,20,60, 80 and $100 \mathrm{mg} /$ L. It follows from the data obtained in Fig. 1 that degradation of pyridine depends upon sonication time. The removal rates of pyridine at $180 \mathrm{~min}$ sonication time were found to decrease from 53 to $15 \%$ with increasing the initial concentration from 10 to $100 \mathrm{mg} / \mathrm{L}$. This suggests that increasing the initial concentration of the solution would decrease the removal rates of pyridine. This is because the increment of initial concentration of the

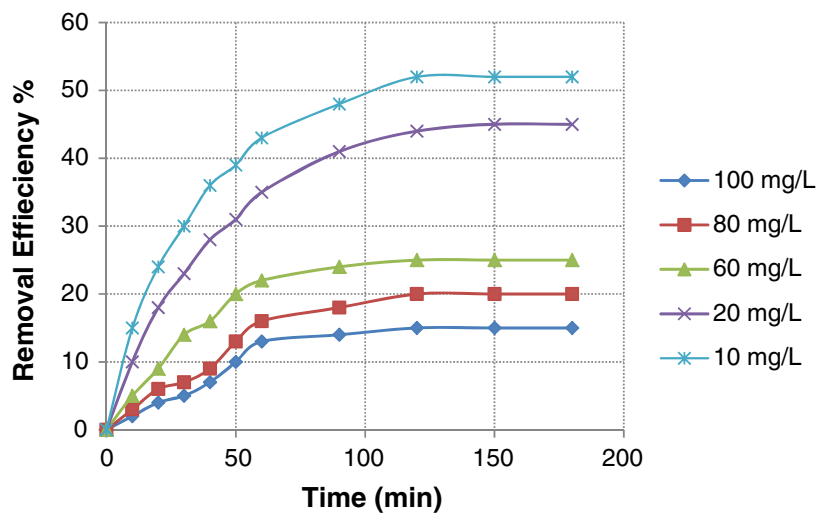

Fig. 1 Pyridine removal efficiencies versus time by ultrasound at various initial concentrations 
volatiles results in the weakening effect of cavitation reactions (Stapleton et al. 2007). However, the total amount of pyridine degraded after $60 \mathrm{~min}$ at $100 \mathrm{mg} / \mathrm{L}$ was as much as three times larger than that degraded at $10 \mathrm{mg} / \mathrm{L}$.

The degradation rates can be expressed by the following equation:

$\ln C_{t} / C_{O}=-K t$

where $C_{0}$ and $C_{\mathrm{t}}$ are the initial and remaining concentrations of pyridine, respectively, $k$ is the degradation rate constant, and $t$ is the sonication time.

A typical $\ln C_{\mathrm{t}} / C_{0}$ vs. $t$ Fig. 2 show that, the reaction kinetics for the degradation followed first order rate laws $\left(R^{2}>93\right)$ at all initial concentrations. In addition to, as it is seen from the Fig. 3, the apparent first order rate constants decreased with an increasing initial concentration of the pyridine, indicating non-elementary nature of the sonochemical reactions. This dependence of reaction rate constants on initial concentration compared well with existing literature (Zechmeister and Magoon 1956; Stapleton et al. 2006, 2007).

Sonochemical degradation is based on physicochemical processes that produce in situ powerful free radical species,

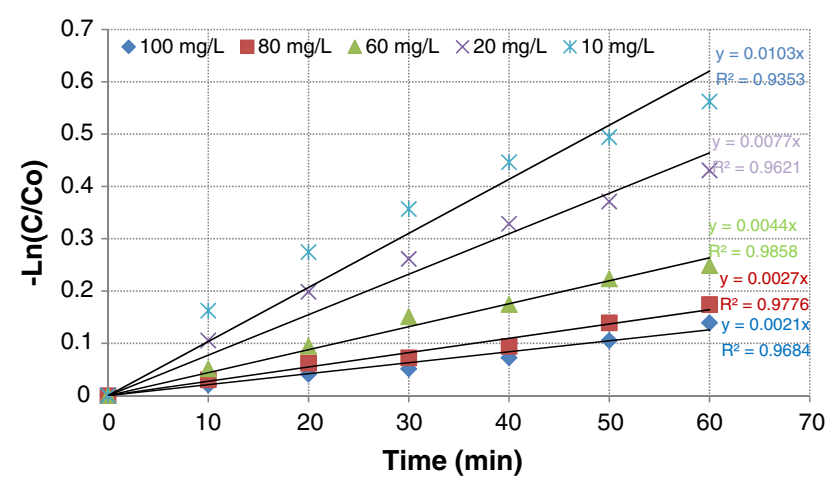

Fig. 2 The first order kinetic of pyridine degradation $(40 \mathrm{kHz}$, $20 \pm 1{ }^{\circ} \mathrm{C}$ and $360 \mathrm{~W}$ )

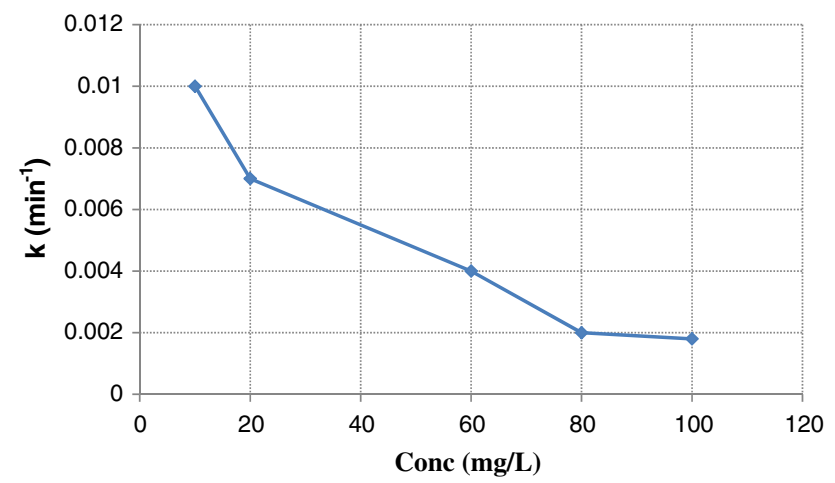

Fig. 3 Apparent first order rate constants vs. initial concentration of pyridine $\left(40 \mathrm{kHz}, 20 \pm 1{ }^{\circ} \mathrm{C}\right.$ and $\left.360 \mathrm{~W}\right)$ principally hydroxyl radicals (HO-), using chemical and/or other forms of energy, and have a high efficiency for organic matter oxidation;. It is highly powerful oxidizing agent having an oxidation potential of $2.33 \mathrm{~V}$, which can undergo rapid and non-selective reaction with most organic and many inorganic pollutant. Hydroxyl radicals exhibit faster rates of oxidation reactions comparing to conventional oxidants such as $\mathrm{H}_{2} \mathrm{O}_{2}$ or $\mathrm{KMnO}_{4}$. Once generated, the hydroxyl radicals can attack organic chemicals by radical addition. The reaction conditions vary as the concentration of monocyclic aromatic compounds in aqueous solution changes. In our case, products formed by the degradation of pyridine should affect the reaction rate due to their influence on the cavitation temperature; however, it is difficult to evaluate and establish (De Visscher et al. 1996).

It seems that the major route for degradation of pyridine during ultrasonic irradiation alone without any additives is by pyrolytic reactions in the gas phase, and thus it shows a greater dependence on initial concentration. Ultrasonication not only promotes oxidative degradation of pyridine by hydroxyl radicals, but also provides a possible route for thermal decomposition in the gas phase (Naffrechoux et al. 2000).

\section{Effect of initial pyridine solution $\mathrm{pH}$}

In this part of study, sonication experiments were repeated with pyridine solutions $100 \mathrm{ppm}$ to study the effect of $\mathrm{pH}$ on the degradation reaction. The initial $\mathrm{pH}$ of the solution was adjusted by adding 1-3 drops of $\mathrm{NaOH}$ $(0.1 \mathrm{M})$ and $\mathrm{HCl}(0.1 \mathrm{M})$. Figure 4 illustrates the removal of pyridine at different $\mathrm{pH}$ initial values. It is seen that $\mathrm{pH}$ value greatly affects the removal efficiencies for pyridine. The optimal $\mathrm{pH}$ was found to be 9 which resulted in $25 \%$ pyridine removal after 180 min pyridine ultrasound (US) radiation. No significant increase of pyridine removal was observed when solution $\mathrm{pH}$ was further increased over 9. However, at acidic medium $(\mathrm{pH}<6.5)$ the removal efficiency decreased considerably. This could be attributed to that, Pyridine is a heterocyclic nitrogenous compound and during its degradation, the $\mathrm{N}$ atom in the pyridine ring upon mineralization is released as ammonia which easily observed by its unpleasant odor. However, because pyridine contains an $\mathrm{N}$ atom, which is more electronegative than an $\mathrm{SP}^{2}$ hybridized $\mathrm{C}$ atom, it is suggested that at higher acidity values, the formation of pyridinium salt predominate, which is more stable in solution. In addition to, in alkaline medium, the anionic state of compound favors the ultrasonic absorption and production of more hydroxyl radical from hydroxyl ion $\left(\mathrm{OH}^{-} \rightarrow \mathrm{OH} \cdot\right)$, which causes the enhancement in degradation efficiency. 


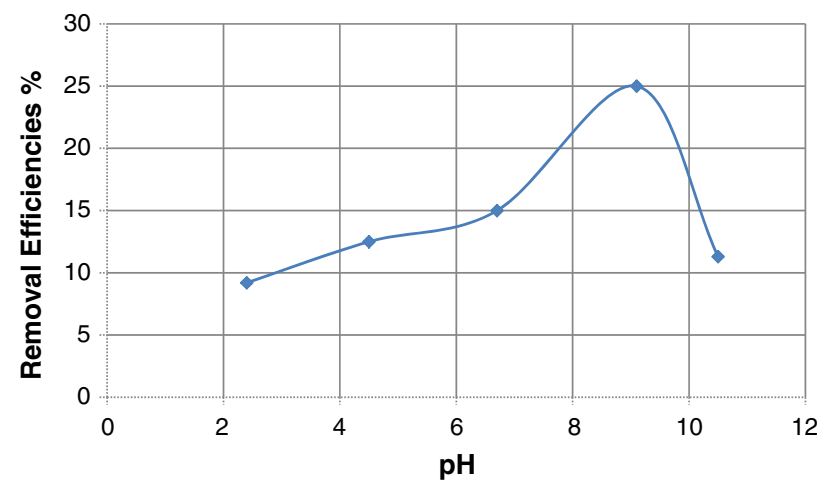

Fig. 4 Effect of the $\mathrm{pH}$ on the removal efficiencies of pyridine by ultrasound $\left(40 \mathrm{kHz}, 20 \pm 1{ }^{\circ} \mathrm{C}\right.$ and $\left.360 \mathrm{~W}\right)$

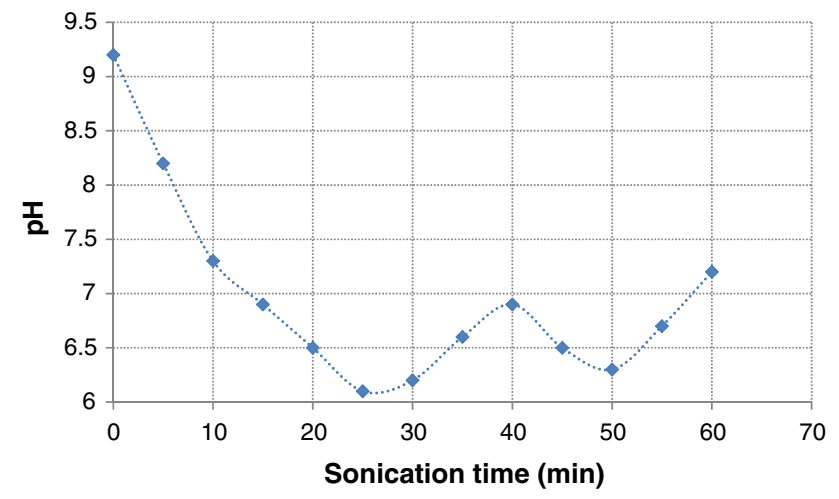

Fig. 5 Variation of pyridine solution $\mathrm{pH}$ with sonication time $\left(40 \mathrm{kHz}, 20 \pm 1{ }^{\circ} \mathrm{C}\right.$ and $360 \mathrm{~W}$ )

On the other hand, by observing the change of $\mathrm{pH}$ value with the sonication time up to $60 \mathrm{~min}$, it was observed that $\mathrm{pH}$ of the sonicated pyridine aqueous mixture has decreased from 9.2 to 6.2 during the irradiation (Fig. 5). Initially at zero time, $\mathrm{pH}$ of the aqueous mixture is found to be 9.2 , which has reduced to 6.2 in the first $25 \mathrm{~min}$ of sonication. The decrease in the $\mathrm{pH}$ may be attributed due to the formation of peroxy radicals in the solution and subsequently formation of oxygen free radicals and the $\left(\mathrm{H}^{+}\right)$ions (Sistla 2005). Many researchers reported the possibility of release of $\left[\mathrm{H}^{+}\right]$ions after $10 \mathrm{~min}$ of irradiation in water. After $15 \mathrm{~min}$ of sonication, $\mathrm{pH}$ values obtained are nearing 7.2 (Stapleton et al. 2007; Sistla and Chintalapati 2008).

The effect of $\mathrm{pH}$ value could be interpreted that $\mathrm{pH}$ value affects the distribution of the existing state of the pyridine and all kinds of organic compounds in the wastewater. It is well known that $\mathrm{pH}$ value can affect the physicochemical properties of substances in aqueous solution, and thus it is expected that $\mathrm{pH}$ value can affect the ultrasonic decomposition rates of substance $\mathrm{s}$ in the solution (Xu et al. 2005). This dependence of degradation on $\mathrm{pH}$ compared well with existing literature. Kotronarou et al. (1991) and Jain et al. (2004) investigated the influence of the changes in the initial
$\mathrm{pH}$ of the pnitrophenol (PNP) solutions on the decay of PNP. PNP decayed exponentially with time at all $\mathrm{pH}$ values. The pseudo-first order rate constant decreased with the increase of $\mathrm{pH}$ (pH 5 to 8), and remained constant up to $\mathrm{pH} 10$. At $\mathrm{pH}>10$, the pseudo-first order rate constant increased slightly because of the slow thermal reaction between PNP and $\mathrm{OH}$ radical $/ \mathrm{H}_{2} \mathrm{O}_{2}$.

Furthermore, Drijvers et al. (1996) found that the degradation of trichloroethylene is fastest in basic solutions. However, no influence of the $\mathrm{pH}$ value of the aqueous solutions on the sonolysis of chlorobenzene was found (Drijvers et al. 1998).

In conclusion, at acidic medium, the formation of salts reduces the vapor pressure of the reactants to such an extent that they are unable to enter the bubbles present and are, hence, unaffected by the ultrasonic waves (Currell et al. 1963).

\section{Effect of ultrasound (US) radiation with and without aeration}

The cavitational effect of ultrasound causes the degassing of liquids. Therefore, many researchers deliberately bubble gas through a sonochemical reaction to facilitate uniform cavitation (Kotronarou et al. 1991). To determine the effect of dissolved gas, experiments were carried out in air saturated solutions. For these experiments, the test gas was introduced into the reactor during the sonication experiments $1.5 \mathrm{~L} \mathrm{~min}^{-1}$. Figure 6 illustrates the removal of pyridine with and without aeration for pyridine concentration $100 \mathrm{ppm}, \mathrm{pH}$ 9.1. It could be seen that the removal was enhanced by aeration to some extent. Aeration brought a lot of air bubbles into the solution. This might result in turbulence and agitation. Therefore, the mass transfer in the solution was enhanced, which benefited the volatile of molecular decomposition product. So, the simultaneous aeration could improve pyridine removal efficiency of ultrasound irradiation by $24 \%$. Though the oxidation of organic pollutants by air is minimal, aeration could disturb pyridine strongly and may even break the surface continuity of pyridine, thus resulting in more cavitation nuclei in pyridine and much more efficient mass transfer and so more degradation of organic pollutants. When ultrasound irradiation is combined with aeration, aeration increases the concentration of cavitation bubbles in solution, enhancing the effective utilization of ultrasound energy, accelerating cavitation and pyrolysis. And at the same time, the cavitation bubbles are broken into 'mini-bubbles'. The total surface area of mini-bubbles is more than 103-104 times higher than that of cavitation bubbles (Xu et al. 2005). So the interfacial area between air and water was increased, and pyridine removal increased. 


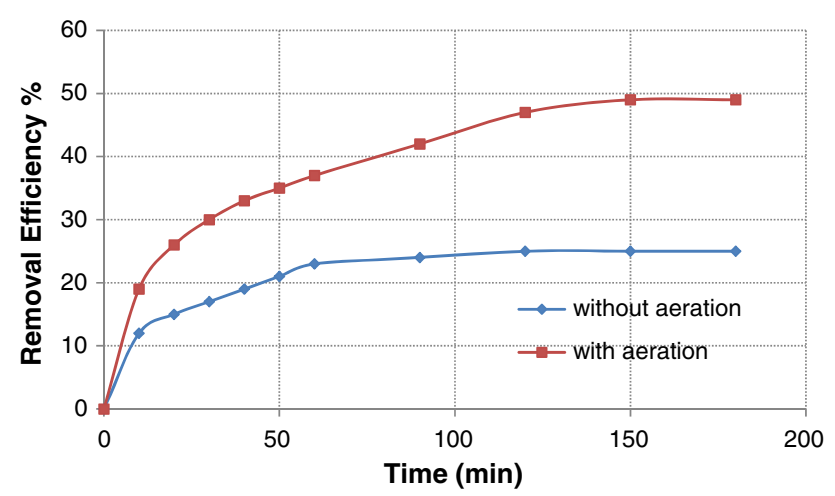

Fig. 6 Effect of dissolved gas on the degradation of $100 \mathrm{ppm}$ pyridine solution $\left(40 \mathrm{kHz}, 20 \pm 1^{\circ} \mathrm{C}, \mathrm{pH} 9.1\right.$ and $\left.360 \mathrm{~W}\right)$

On the other hand, If the solution is saturated with oxygen, additional reactions occur as a consequence of combination of molecular oxygen with hydrogen atoms and the thermal decomposition of oxygen in the gas phase according to Eqs. (2)-(8) (Pang et al. 2011). In these reactions ")))" denotes the US irradiation. These reactions produce higher hydroxyl radical concentration, which cause more degradation of pyridine

$$
\begin{aligned}
& \left.\left.\left.\mathrm{H}_{2} \mathrm{O}+\right)\right)\right) \rightarrow \cdot \mathrm{OH}+\cdot \mathrm{H} \\
& \left.\mathrm{O}_{2}(\text { dissolved })+()\right) \rightarrow 2 \cdot \mathrm{O} \\
& \mathrm{O}_{2}+\cdot \mathrm{H} \rightarrow \cdot \mathrm{O}_{2} \mathrm{H} \\
& \mathrm{O}+\cdot \mathrm{O}_{2} \mathrm{H} \rightarrow \cdot \mathrm{OH}+\mathrm{O}_{2} \\
& \mathrm{O}_{2}+\mathrm{O} \rightarrow \mathrm{O}_{3} \\
& \mathrm{O}+\mathrm{H}_{2} \mathrm{O} \rightarrow 2 \cdot \mathrm{OH} \\
& \cdot \mathrm{O}_{2} \mathrm{H}+\cdot \mathrm{O}_{2} \mathrm{H} \rightarrow \mathrm{H}_{2} \mathrm{O}_{2}+\mathrm{O}_{2}
\end{aligned}
$$

Furthermore, many investigators have extensively stated that dissolved gases are essential for the sonochemical reaction. Griffing (2004) noted that the rate of the hydrolysis of $\mathrm{CCl}_{4}$ is strongly dependent on the dissolved gas. Weissler et al. (1950) confirmed the effect of dissolved gases $\left(\mathrm{O}_{2}, \mathrm{~N}_{2}, \mathrm{He}, \mathrm{CO}_{2}\right.$, vacuum) on the iodine yields during the ultrasonic irradiation of KI solutions in the absence of $\mathrm{CCl}_{4}$ and with a large excess of $\mathrm{CCl}_{4}$.

\section{Effect of sonochemical reaction temperature}

The effect of media temperature on pyridine degradation was investigated at an initial pyridine concentration of $100 \mathrm{ppm}$, $\mathrm{pH}$ of 9.1, air flow at $1.5 \mathrm{~L} \mathrm{~min}^{-1}$, and power of $360 \mathrm{~W}$. Three different temperatures were utilized to investigate the influence of operating temperature on the cavitation reactions. The media temperature in solution gradually increases when ultrasound starts to operate, due to the thermal energy from ultrasound irradiation; therefore a water circulating system was needed to keep the operating temperature stable. Actual

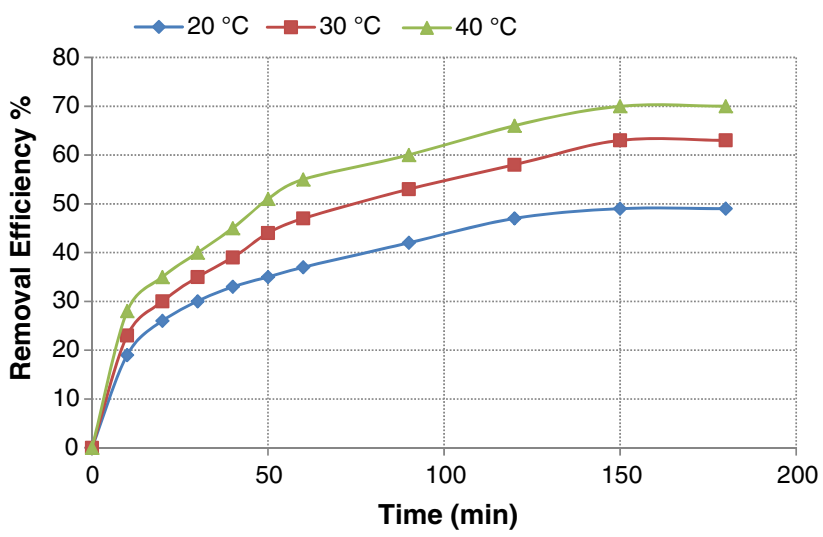

Fig. 7 Effect of media temperature on the degradation of the pyridine (pyridine concentration $100 \mathrm{ppm}$, air flow $1.5 \mathrm{~L} \mathrm{~min}^{-1}$, $\mathrm{pH} 9.1$, $40 \mathrm{kHz}$ and $360 \mathrm{~W}$ )

temperatures measured inside of the reaction container were 20,30 , and $40^{\circ} \mathrm{C}$. Temperature error was manipulated within $2{ }^{\circ} \mathrm{C}$. The results are illustrated in Fig. 7. With increasing media temperatures, the removal efficiencies of pyridine increased in the temperature range in this study. Generally speaking, the chemical reaction rate usually increases as temperature rises, the liquid temperature and applied pressure dramatically affect the sonochemical reaction rates. The bulk temperature and static pressure first affect the vapor pressure, gas solubility, components in cavities, and thermal activation. Thereby, the intensity of collapse and the secondary reaction rate are influenced (Naffrechoux et al. 2000).

On the other hand, the effective maximum temperature generated during the cavitational collapse is inversely proportional to the vapor pressure. A bubble contains not only the gas that is dissolved in the liquid, but also vapor from the liquid itself. The amount of vapor in the bubble depends on the vapor pressure of the liquid, which is strongly dependent on the temperature of the bulk liquid. Combining all of the above, the effect of temperature on sonochemical degradation rate is complicated. Thus, there is no consistent report on the impact of temperature on the degradation of organic compounds in literature. Bhatnagar and Cheung (1994) reported that the degradation of trichloroethylene and carbon tetrachloride remained constant between -7 to 20 and 20-60 ${ }^{\circ} \mathrm{C}$, respectively. In contrast, Destaillats et al. (2000) indicated that the sonochemical degradation of chlorobenzene and TCE, respectively, increased with increasing temperature. In this study, slightly higher degradation is achieved at higher temperatures.

\section{Conclusion}

Ultrasonic irradiation has the potential for use in environmental decontamination due to the production of high 
concentrations of oxidizing species such as $\cdot \mathrm{OH}$ and $\mathrm{H}_{2} \mathrm{O}_{2}$, in the solution and localized transient high temperatures and pressures. It does not require the addition of chemical additives to achieve viable degradation rates. However, by carefully adjusting the operating conditions, the degradation efficiency can be significantly increased. In this study, sonochemical degradation of pyridine under different process parameters was conducted. Effects of different process variables such as initial concentration, $\mathrm{pH}$, aeration, and media temperature were tested. The reaction rate was observed to be a function of the initial concentration of the pyridine. It decreases with the increase in initial concentration. The degradation efficiency of pyridine increases with the increasing of the reaction temperature, the initial $\mathrm{pH}$, and aeration. The research has shown that it is technically feasible to decompose pyridine compound by sonolysis. The advantage of ultrasonic degradation lies in the amount of energy stored in the microbubbles. If properly utilized, it can be a truly useful technology for large scale water treatment. The process is easier to operate and there are practically no hazards associated with it.

Open Access This article is distributed under the terms of the Creative Commons Attribution License which permits any use, distribution, and reproduction in any medium, provided the original author(s) and the source are credited.

\section{References}

Abbasi M, Asl NR (2008) Sonochemical degradation of Basic Blue 41 dye assisted by nanoTiO2 and $\mathrm{H} 2 \mathrm{O} 2$. J Hazard Mater 153(3):942-947. doi:10.1016/j.jhazmat.2007.09.045

Agustina TE, Ang HM, Vareek VK (2005) A review of synergistic effect of photocatalysis and ozonation on wastewater treatment. J Photochem Photobiol C Photochem Rev 6(4):264-273. doi:10. 1016/j.jphotochemrev.2005.12.003

Bhatnagar A, Cheung HM (1994) Sonochemical destruction of chlorinated $\mathrm{C} 1$ and $\mathrm{C} 2$ volatile organic compounds in dilute aqueous solution. Environ Sci Technol 28(8):1481-1486

Currell DL, Wilheim G, Nagy S (1963) The effect of certain variables on the ultrasonic cleavage of phenol and of pyridine. J Am Chem Soc 85(2):127-130. doi:10.1021/ja00885a002

De Visscher A, Van Eenoo P, Drijvers D, Van Langenhove H (1996) Kinetic model for the sonochemical degradation of monocyclic aromatic compounds in aqueous solution. J Phys Chem 100(28):11636-11642. doi:10.1021/jp953688o

Destaillats H, Colussi A, Joseph JM, Hoffmann MR (2000) Synergistic effects of sonolysis combined with ozonolysis for the oxidation of azobenzene and methyl orange. J Phys Chem A 104(39):8930-8935

Drijvers D, De Baets R, De Visscher A, Van Langenhove H (1996) Sonolysis of trichloroethylene in aqueous solution: volatile organic intermediates. Ultrason Sonochem 3(2):S83-S90

Drijvers D, Van Langenhove H, Vervaet K (1998) Sonolysis of chlorobenzene in aqueous solution: organic intermediates. Ultrason Sonochem 5(1):13-19

Goel M, Hongqiang H, Mujumdar AS, Ray MB (2004) Sonochemical decomposition of volatile and non-volatile organic compounds: a comparative study. Water Res 38(19):4247-4261. doi:10.1016/j. watres.2004.08.008

Gogate PR, Pandit AB (2004) A review of imperative technologies for wastewater treatment I: oxidation technologies at ambient conditions. Adv Environ Res 8(3-4):501-551. doi:10.1016/ S1093-0191(03)00032-7

Gong C, Hart DP (1998) Ultrasound induced cavitation and sonochemical yields. J Acousti Soc Am 104(5):2675-2682. doi: $10.1121 / 1.423851$

Griffing V (2004) The chemical effects of ultrasonics. J Chem Phys 20(6):939-942

Gupta VK, Sharma S (2003) Removal of zinc from aqueous solutions using bagasse fly ash-a low cost adsorbent. Ind Eng Chem Res 42(25):6619-6624

Gupta VK, Mittal A, Kurup L, Mittal J (2006) Adsorption of a hazardous dye, erythrosine, over hen feathers. J Colloid Interface Sci 304(1):52-57

Gupta V, Jain R, Mittal A, Mathur M, Sikarwar S (2007a) Photochemical degradation of the hazardous dye Safranin-T using $\mathrm{TiO}_{2}$ catalyst. J Colloid Interface Sci 309(2):464-469

Gupta VK, Ali I, Saini VK (2007b) Defluoridation of wastewaters using waste carbon slurry. Water Res 41(15):3307-3316

Gupta VK, Jain R, Varshney S (2007c) Electrochemical removal of the hazardous dye Reactofix Red 3 BFN from industrial effluents. J Colloid Interface Sci 312(2):292-296

Gupta VK, Mittal A, Malviya A, Mittal J (2009) Adsorption of carmoisine A from wastewater using waste materials-bottom ash and deoiled soya. J Colloid Interface Sci 335(1):24-33

Gupta VK, Rastogi A, Nayak A (2010) Adsorption studies on the removal of hexavalent chromium from aqueous solution using a low cost fertilizer industry waste material. J Colloid Interface Sci 342(1):135-141

Gupta V, Gupta B, Rastogi A, Agarwal S, Nayak A (2011) A comparative investigation on adsorption performances of mesoporous activated carbon prepared from waste rubber tire and activated carbon for a hazardous azo dye-Acid Blue 113. J Hazard Mater 186(1):891-901

Gupta VK, Mittal A, Jhare D, Mittal J (2012) Batch and bulk removal of hazardous colouring agent Rose Bengal by adsorption techniques using bottom ash as adsorbent. RSC Adv 2(22):8381-8389

Ince NH, Tezcanlí G (2001) Reactive dyestuff degradation by combined sonolysis and ozonation. Dyes Pigments 49(3): 145-153. doi:10.1016/S0143-7208(01)00019-5

Jain AK, Gupta VK, Jain S, Suhas (2004) Removal of chlorophenols using industrial wastes. Environ Sci Technol 38(4):1195-1200

Karthikeyan S, Gupta V, Boopathy R, Titus A, Sekaran G (2012) A new approach for the degradation of high concentration of aromatic amine by heterocatalytic Fenton oxidation: kinetic and spectroscopic studies. J Mol Liq 173:153-163

Kotronarou A, Mills G, Hoffmann MR (1991) Ultrasonic irradiation of p-nitrophenol in aqueous solution. J Phys Chem 95(9):3630-3638

Mathur AK, Majumder CB, Chatterjee S, Roy P (2008) Biodegradation of pyridine by the new bacterial isolates $S$. putrefaciens and B. sphaericus. J Hazard Mater 157(2-3):335-343. doi:10. 1016/j.jhazmat.2007.12.112

Mittal A, Gupta V, Malviya A, Mittal J (2008) Process development for the batch and bulk removal and recovery of a hazardous, water-soluble azo dye (Metanil Yellow) by adsorption over waste materials (Bottom Ash and De-Oiled Soya). J Hazard Mater 151(2):821-832

Mittal A, Mittal J, Malviya A, Kaur D, Gupta V (2010) Adsorption of hazardous dye crystal violet from wastewater by waste materials. J Colloid Interface Sci 343(2):463-473

Naffrechoux E, Chanoux S, Petrier C, Suptil J (2000) Sonochemical and photochemical oxidation of organic matter. Ultrason Sonochem 7(4):255-259. doi:10.1016/S1350-4177(00)00054-7 
Padoley KV, Rajvaidya AS, Subbarao TV, Pandey RA (2006) Biodegradation of pyridine in a completely mixed activated sludge process. Bioresourc Technol 97(10):1225-1236. doi:10. 1016/j.biortech.2005.05.020

Pang YL, Abdullah AZ, Bhatia S (2011) Review on sonochemical methods in the presence of catalysts and chemical additives for treatment of organic pollutants in wastewater. Desalination 277(1-3):1-14. doi:10.1016/j.desal.2011.04.049

Saleh TA, Gupta VK (2012) Column with CNT/magnesium oxide composite for lead (II) removal from water. Environ Sci Pollut Res 19(4):1224-1228

Sistla S (2005) Degradation of Pyridine by ultrasound: a common refractory pollutant in wastewater effluents. Asian $\mathrm{J}$ Water Environ Pollut 2(2):89-93

Sistla S, Chintalapati S (2008) Sonochemical degradation of Congo red. Int J Environ Waste Manage 2(3):309-319

Stapleton DR, Emery RJ, Mantzavinos D, Papadaki M (2006) Photolytic destruction of halogenated pyridines in wastewaters. Process Saf Environ Protect 84(4):313-316. doi:10.1205/psep. 05164

Stapleton DR, Mantzavinos D, Papadaki M (2007) Photolytic (UVC) and photocatalyic (UVC/TiO2) decomposition of pyridines.
J Hazard Mater 146(3):640-645. doi:10.1016/j.jhazmat.2007. 04.067

Vinodgopal K, Peller J, Makogon O, Kamat PV (1998) Ultrasonic mineralization of a reactive textile azo dye, remazol black B. Water Res 32(12):3646-3650. doi:10.1016/S0043-1354(98) 00154-7

Weissler A, Cooper HW, Snyder S (1950) Chemical effect of ultrasonic waves: oxidation of potassium iodide solution by carbon tetrachloride. J Am Chem Soc 72(4):1769-1775

Xu J, Jia J, Wang J (2005) Ultrasonic decomposition of ammonianitrogen and organic compounds in coke plant wastewater. J Chin Chem Soc 52(1):59-65

Yang S, Wang P, Yang X, Wei G, Zhang W, Shan L (2009) A novel advanced oxidation process to degrade organic pollutants in wastewater: Microwave-activated persulfate oxidation. J Environ Sci 21(9):1175-1180. doi:10.1016/S1001-0742(08)62399-2

Zechmeister L, Magoon EF (1956) On the ultrasonic cleavage of the pyridine ring. J Am Chem Soc 78(10):2149-2150. doi:10.1021/ ja01591a031 